\title{
The relationship of SSRI and SNRI usage with interstitial lung disease and bronchiectasis in an elderly population: a case-control study
}

This article was published in the following Dove Press journal:

Clinical Interventions in Aging

Number of times this article has been viewed

\section{Ted Rosenberg' \\ Rory Lattimer ${ }^{2}$ \\ Patrick Montgomery ${ }^{3}$ \\ Christian Wiens ${ }^{4}$ \\ Liran Levy ${ }^{5}$}

'Department of Family Medicine, University of British Columbia and Island Medical Program,Victoria, BC, ${ }^{2}$ Home Team Medical Services, Victoria, BC, ${ }^{3}$ Division of Geriatric Medicine, University of British Columbia, Victoria, BC, ${ }^{4}$ Geriatric Psychiatry, University of British Columbia, Victoria, BC, ${ }^{5}$ Lung Transplant Program, Toronto General Hospital, Toronto, ON, Canada
Correspondence: Ted Rosenberg Department of Family Practice, University of British Columbia, 996 Abbey Road, Victoria, BC V8Y IL2, Canada

Tel +I 2506580554

Fax +I 8886692916

Email trosenberg@hometeammedical.ca
Background: The association between interstitial lung disease (ILD) and selective serotonin reuptake inhibitors and serotonin norepinephrine reuptake inhibitors (SSRI/SNRI) has been previously described in published case reports. However, its prevalence may be more common than expected. We examined the association between SSRI/SNRI usage and presence of ILD and or bronchiectasis (ILD/B) in an elderly population.

Methods: We conducted a retrospective case series and case-control study involving all 296 eligible elderly patients in one primary care geriatric practice in Victoria, BC, Canada. Cases required the presence of ILD/B on computed tomography (CT) or chest X-ray (CXR). Cases were excluded if they had other causes for ILD/B on CXR or CT such as exposure to known pneumotoxic drugs, metastatic cancer, rheumatoid lung disease, sarcoidosis, previous pulmonary tuberculosis, or pneumoconiosis. Data were abstracted from the patients' medical record. The exposure variable was standardized cumulative person-month (p-m) dose of SSRI/SNRI. The study was approved by the Clinical Research Ethics Board of University of British Columbia with a waiver of informed consent.

Results: A total of 12 cases and 273 controls were identified. Their mean ages were 89.0 and 88.7 years, respectively ( $p=0.862$ ). A total of $10 / 12$ cases and $99 / 273$ controls were exposed to SSRI/SNRI. The odds ratio was $8.79,95 \%$ confidence interval $2.40-32.23$ ( $p=0.001)$. The median p-m exposure to SSRI/SNRI was 110.0 months for cases and 29.5 for controls $(p=0.003)$.

Conclusion: SSRIs and SNRIs were significantly associated with the risk of ILD/B in this elderly population. Because of their widespread usage, further studies should be done to validate these findings. Prescribers should cautiously monitor patients for development of insidious pulmonary symptoms when these drugs are used.

Keywords: SSRI, SNRI, antidepressant, interstitial lung disease, aging, geriatric psychiatry

\section{Introduction}

Prescription drug use is increasing in all adult age groups in the USA, ${ }^{1}$ and antidepressants (ADs) are the third most commonly prescribed medications. ${ }^{1,2}$ It is estimated that $17 \%$ of the USA population aged $>60$ years takes an $\mathrm{AD}^{1}$ and that $89 \%$ of elderly people aged $\geq 65$ years in general practices in the UK with a diagnosis of depression have been given at least one prescription for an AD. ${ }^{3}$ Furthermore, 60\% of people take ADs for $\geq 2$ years and $14 \%$ are on $A D s$ for $\geq 10$ years. $^{2}$ The mean duration of AD use for elderly people in the UK study was 364 days. ${ }^{3}$ The prevalence of AD usage has increased to $46.2 \%$ for residents of American nursing homes. ${ }^{4}$ The overall prevalence of AD usage increased by 400\% in the USA between 1988-1994 and $2005-2008{ }^{2}$ 
Selective serotonin reuptake inhibitors (SSRIs) and serotonin norepinephrine reuptake inhibitors (SNRIs) are the most commonly prescribed ADs because of their lower side effect profile compared to older drugs such as tricyclic antidepressants (TCADs). ${ }^{3,4}$ However, a UK study documented an increased total mortality in elderly SSRI users compared to TCADs and non-users of ADs. ${ }^{3}$

SSRIs and SNRIs are listed as sources of interstitial lung disease (ILD) and airway pathology on the Pneumotox website (www.pneumotox.com), which tracks drug-induced lung diseases. There have been case reports linking SSRIs and SNRIs to asthma, ${ }^{5}$ bronchiolitis, ${ }^{6}$ eosinophilic pneumonia, ${ }^{7-11}$ pneumonitis, ${ }^{12,13}$ granulomatous pneumonia, ${ }^{14}$ diffuse alveolar damage ${ }^{15}$ and pulmonary scarring, ${ }^{16}$ and pneumonitis with cardiomyopathy. ${ }^{13,17}$ Studies have shown that the prevalence of ILD is more common than thought ${ }^{18,19}$ and that mortality from ILD is increasing. ${ }^{20,21}$ A Danish study showed that the incidence was increasing in the general population and was highest in the elderly group. ${ }^{22}$ A recent study of the Framingham cohort has shown that interstitial lung abnormalities (ILA) were not uncommon and $6 \%$ of all participants showed progressive ILA on serial high-resolution computerized tomography (HRCT) scanning over a 6-year period with reduced lung capacity, reduced exercise tolerance, and higher mortality. ${ }^{23} \mathrm{We}$ report a case series and case-control study examining the association between SSRI and SNRI usage and ILD and/or bronchiectasis (ILD/B) on chest X-ray (CXR) and computed tomography (CT) scans in an elderly population.

\section{Methods}

\section{Study design}

The study was a retrospective chart review with case-control analyses.

\section{Study population}

The study included all 296 elderly people in a primary care home-based geriatric practice. ${ }^{24}$ This practice model includes a team that provides primary medical care to frail elderly people living in the community. The team includes a clinical care manager, physician, nurse, physiotherapist, and rehabilitation/exercise aide. Eligibility criteria included age 70 years or older, not living in a nursing home, difficulty accessing usual medical care, and having a frailty syndrome (eg, mobility problems or cognitive impairment) and/or complex multiple comorbidities/polypharmacy. Patients are followed up until they die or move to a nursing home.
A minority continue to be followed up in a few selected nursing homes in Victoria.

Patients were active members of the practice as of February 1, 2016 when data were abstracted. A total of $144(50.3 \%)$ people were living in houses or apartments, $108(37.8 \%)$ living in retirement homes or assisted living facilities, and $34(11.9 \%)$ living in nursing homes. The median length of stay (LOS) in the practice was 27 months (range 1-146 months).

\section{Data sources}

The electronic medical record was audited for age, sex, estimated glomerular filtration rate (eGFR), type and duration of AD usage, smoking status, Clinical Frailty Scale (CFS), ${ }^{25}$ and CXR and CT reports.

\section{Case definition}

Cases required radiological evidence (RE) of ILD/B on CXR or CT. RE was defined as the reported presence of fibrosis, scarring, interstitial lung changes, or bronchiectasis. Reports of isolated atelectasis, pleural plaques, asbestosis, and acute pneumonia were not counted as cases. CXRs and CT scans were performed as part of usual care and ordered if patients had symptoms and clinical disease but not for the purposes of this study. A total of 173/286 (60.1\%) participants had CXRs and 31/286 (10.8\%) had CT scans. CXRs and CTs were reported by radiologists as part of routine clinical care and blinded to AD usage.

\section{Exclusion criteria}

Cases were excluded if they had potentially confounding factors that could cause ILD/B. Eleven cases (3.9\% of total) were excluded for the following reasons: metastatic cancer $(n=2)$, silicosis/asbestosis $(n=3)$, old pulmonary tuberculosis (TB) $(n=3)$, brainstem stroke with severe dysphagia and chronic aspiration $(n=1)$, and pneumotoxic drugs, methotrexate $(n=2)$ or hydralazine $(n=1)$. Six excluded cases were exposed to SSRI/SNRI and five were not. None of the cases were on chronic nitrofurantoin and amiodarone or had chest radiation. Cases 1, 5, and 9 (Table 1) used an angiotensin-converting enzyme inhibitor or angiotensin receptor blocker but did not experience chronic cough. They were not excluded from the analyses.

\section{$A D$ usage}

Each individual patient's chart was audited for the following ADs using both generic and trade names: venlafaxine, duloxetine, citalopram, escitalopram, sertraline, fluoxetine, 
Table I Cases

\begin{tabular}{|c|c|c|c|c|c|c|c|c|c|c|}
\hline Case & $\begin{array}{l}\text { Age, } \\
\text { years }\end{array}$ & Sex & $\begin{array}{l}\text { Smoking } \\
\text { history }\end{array}$ & $\begin{array}{l}\text { Primary } \\
\text { symptoms }\end{array}$ & CXR & CT & $\begin{array}{l}\text { p-m } \\
\text { exposure }\end{array}$ & $\begin{array}{l}\text { Estimated } \\
\text { latency* }\end{array}$ & Drug & $\begin{array}{l}\text { Impact after } \\
\text { stopping }\end{array}$ \\
\hline 1 & 93 & $\mathrm{~F}$ & Yes & $\begin{array}{l}\text { Fatigue, } \\
\text { dyspnea }\end{array}$ & $\begin{array}{l}\text { Diffuse pulmonary } \\
\text { fibrosis }\end{array}$ & $\begin{array}{l}\text { Central bronchiectasis } \\
\text { and scarring }\end{array}$ & 128 & 78 & Venlafaxine & Improvement \\
\hline 2 & 90 & $\mathrm{~F}$ & Yes & Fatigue & No lung disease & $\begin{array}{l}\text { Bilateral peripheral } \\
\text { sub-pleural reticular } \\
\text { opacity consistent with } \\
\text { pulmonary fibrosis }\end{array}$ & 287 & 72 & $\begin{array}{l}\text { Venlafaxine, } \\
\text { paroxetine }\end{array}$ & Not stopped \\
\hline 3 & 92 & $\mathrm{~F}$ & No & $\begin{array}{l}\text { Cough, } \\
\text { mucous, } \\
\text { dyspnea, } \\
\text { wheeze }\end{array}$ & $\begin{array}{l}\text { Chronic changes are } \\
\text { again noted in both } \\
\text { lung apices and left } \\
\text { lower lobe } \\
\text { Consolidation }\end{array}$ & $\begin{array}{l}\text { Cylindrical } \\
\text { bronchiectasis, ground } \\
\text { glass opacities, fine and } \\
\text { coarse reticulations } \\
\text { nodularity }\end{array}$ & 376 & 19 & $\begin{array}{l}\text { Duloxetine, } \\
\text { venlafaxine }\end{array}$ & Improvement \\
\hline 4 & 75 & $M$ & Yes & Fatigue & No lung disease & $\begin{array}{l}\text { Parenchymal scarring in } \\
\text { lower lobes and pleural } \\
\text { thickening }\end{array}$ & 72 & 54 & $\begin{array}{l}\text { Duloxetine, } \\
\text { citalopram }\end{array}$ & Not stopped \\
\hline 5 & 90 & $\mathrm{~F}$ & Yes & $\begin{array}{l}\text { Dyspnea, } \\
\text { fatigue }\end{array}$ & Left basilar scarring & Not available & 161 & 37 & $\begin{array}{l}\text { Venlafaxine, } \\
\text { duloxetine, } \\
\text { escitalopram }\end{array}$ & Not stopped \\
\hline 6 & 91 & $\mathrm{~F}$ & No & $\begin{array}{l}\text { Dyspnea, } \\
\text { fatigue }\end{array}$ & $\begin{array}{l}\text { Bilateral interstitial } \\
\text { markings in bases } \\
\text { suggestive of } \\
\text { interstitial lung disease }\end{array}$ & Not available & 92 & II & Duloxetine & Not stopped \\
\hline 7 & 88 & $\mathrm{~F}$ & Yes & $\begin{array}{l}\text { Cough, } \\
\text { mucous, } \\
\text { dyspnea, } \\
\text { wheeze }\end{array}$ & $\begin{array}{l}\text { Bilateral coarse } \\
\text { peripheral reticular } \\
\text { interstitial opacities in } \\
\text { lower lobes }\end{array}$ & $\begin{array}{l}\text { Bilateral idiopathic } \\
\text { pulmonary fibrosis with } \\
\text { honeycombing patchy } \\
\text { airspace consolidation, } \\
\text { bronchiectasis in left } \\
\text { lung base }\end{array}$ & 531 & 109 & Fluoxetine & Improvement \\
\hline 8 & 93 & $\mathrm{~F}$ & Yes & $\begin{array}{l}\text { Cough, } \\
\text { mucous, } \\
\text { dyspnea }\end{array}$ & $\begin{array}{l}\text { Left basilar scarring/ } \\
\text { atelectasis }\end{array}$ & $\begin{array}{l}\text { Chronic bronchial } \\
\text { wall thickening, } \\
\text { bilateral lower lobe } \\
\text { bronchiectasis with } \\
\text { inflammatory changes }\end{array}$ & 33 & 19 & Paroxetine & Improvement \\
\hline 9 & 91 & $M$ & No & Fatigue & $\begin{array}{l}\text { Extensive interstitial } \\
\text { markings consistent } \\
\text { with pulmonary } \\
\text { fibrosis }\end{array}$ & None available & 26 & 8 & Paroxetine & No change \\
\hline 10 & 85 & $M$ & Yes & $\begin{array}{l}\text { Fatigue, } \\
\text { cough, wheeze }\end{array}$ & Scarring left lung base & None available & 84 & 35 & Sertraline & Not stopped \\
\hline II & 86 & $\mathrm{~F}$ & Yes & $\begin{array}{l}\text { Cough, fatigue, } \\
\text { dyspnea }\end{array}$ & $\begin{array}{l}\text { Extensive bilateral } \\
\text { reticular interstitial } \\
\text { opacity worse in } \\
\text { periphery and lower } \\
\text { lung zones consistent } \\
\text { with pulmonary } \\
\text { fibrosis }\end{array}$ & $\begin{array}{l}\text { Interstitial changes in } \\
\text { lung peripheries of } \\
\text { upper and lower lobes, } \\
\text { pulmonary fibrosis, } \\
\text { honeycombing in both } \\
\text { bases }\end{array}$ & 0 & $\begin{array}{l}\text { Not } \\
\text { applicable }\end{array}$ & None & $\begin{array}{l}\text { Not } \\
\text { applicable }\end{array}$ \\
\hline 12 & 85 & $\mathrm{~F}$ & Yes & Cough & None available & $\begin{array}{l}\text { Peripheral fibrosis, } \\
\text { honeycombing, traction } \\
\text { bronchiectasis }\end{array}$ & 0 & $\begin{array}{l}\text { Not } \\
\text { applicable }\end{array}$ & None & $\begin{array}{l}\text { Not } \\
\text { applicable }\end{array}$ \\
\hline
\end{tabular}

Note: *Months between initial exposure and first radiological abnormality.

Abbreviations: CXR, chest X-ray; CT, computed tomography; p-m, person-month; F, female; $M$, male.

fluvoxamine, paroxetine, mirtazapine, amitriptyline, nortriptyline, and bupropion. SSRI/SNRI exposure was standardized to $10 \mathrm{mg}$ of citalopram equivalents using the following equivalents based on usual clinical practice: a) $10 \mathrm{mg}$ citalopram; b) $5 \mathrm{mg}$ escitalopram; c) $25 \mathrm{mg}$ sertraline; d) $10 \mathrm{mg}$ fluoxetine; e) $10 \mathrm{mg}$ paroxetine; f) $15 \mathrm{mg}$ duloxetine; and g) $37.5 \mathrm{mg}$ venlafaxine.

Start dates and stop dates for each SSRI/SNRI used by a patient were used to calculate person-months (p-ms) of exposure to an equivalent dose of $10 \mathrm{mg}$ of citalopram. 
The total exposure was summed and included all the different SSRI/SNRIs used during the study period. We did not have access to start dates for patients who were on an $\mathrm{AD}$ at the time of entering the practice. Because $>60 \%$ of people are on ADs for more than 2 years, ${ }^{2}$ we conservatively estimated that they were on these drugs for 12 months at their current dose before they entered the practice.

\section{Other confounding factors}

Charts were audited for dementia or other neurological problems that may cause dysphagia, aspiration, and ILD. Dementia was defined as cognitive impairment that affected daily function. Other neurological problems without dementia included neurodegenerative diseases (eg, multiple sclerosis and Parkinson's disease), strokes, and head/brain injuries with chronic deficits. There were 103 people who had dementia and 41 people who had other central nervous system (CNS) problems without dementia. These were combined into one variable called "neurological problems".

\section{Statistical analyses}

Means, standard deviations, and two-sided $t$-tests were used for continuous data. The $\mathrm{p}-\mathrm{m}$ exposure to SSRI/SNRI was skewed with unequal variance. Therefore, Mann-Whitney $U$ test was used to compare median doses of exposure between cases and controls. Chi-square tests with Yates corrections were used to compare proportions. Fisher's exact test was used if there were $<5$ observations. Odds ratios were calculated, and Mantel-Haenszel test was used to calculate 95\% confidence intervals ( $95 \% \mathrm{CI})$.

Multiple logistic regression was used to test the association between age, GFR, smoking status, neurological problems, $\mathrm{p}-\mathrm{m}$ exposure, and being a case.

Ascertainment bias was estimated by comparing the frequency of CXR and CT testing in cases and controls. Multiple linear regression was used to test the association between the number of CXRs and CTs and case status, SSRI/SNRI exposure, and LOS (in months).

Statistical analyses were done using the Number Cruncher Statistical System V.10 (NCSS) ${ }^{\mathrm{TM}}$ (Kaysville, UT, USA).

\section{Ethics}

The study was approved by the Clinical Research Ethics Board of University of British Columbia (H16-00656) with a waiver of informed consent. Consent was waived because this study was part of an audit, conformed to standards for minimal risk research and did not affect patient safety or clinical care. To protect patient confidentiality, personal identifiers were removed from spreadsheets used for data analyses and all reports. Signed informed consent to publish was obtained from the daughter of the reported index case because the woman was deceased.

\section{Results Index case report}

The index case was a 92-year-old woman. She quit smoking at the age of 57 years. There was no history of cardiac or lung disease. In June 2010, she insidiously developed fatigue and dyspnea with exertion. She had bilateral coarse crackles to mid-lungs, normal jugular venous pressure (JVP), blood pressure (BP), heart rate (HR), and minimal pedal edema. Room air oxygen saturations were $88 \%$ at rest and dropped to $85 \%$ with walking. There was no cough or infection. BNP was elevated to $927 \mathrm{ng} / \mathrm{L}$ (normal < 100), CXR showed mild pulmonary edema, and troponin $t$ was normal. She was given oral furosemide with some improvement in her dyspnea but no change in her severe fatigue. She was seen by a respirologist who identified a restrictive lung disease on pulmonary function tests. HRCT showed apical scarring and central bronchiectasis. Echocardiogram showed pulmonary artery pressure of $58 \mathrm{mmHg}$ and left ventricular ejection fraction of $60 \%$. Continuous $\mathrm{O}_{2}$ was started.

On December 22, 2014, she was found to be depressed. She had been on venlafaxine $37.5 \mathrm{mg}$ OD since May 2004. Venlafaxine was increased to $75 \mathrm{mg}$ OD. On December 23, 2014, there was a severe deterioration in her mobility, fatigue, and breathlessness. There was no cough, fever, or symptoms of acute infection. $\mathrm{O}_{2}$ saturation was $87 \%$ on $2 \mathrm{~L} / \mathrm{m}$, dropping to $80 \%$ with walking. There were bilateral coarse crackles throughout her lungs. Other clinical findings included: JVP $3 \mathrm{~cm}$, HR 68, BP 102/68 mmHg, and +1 edema. CXR was reported as cardiomegaly with diffuse pulmonary fibrosis. BNP was 1,741 ng/L. She refused to undergo CT. Diuresis with furosemide did not improve her symptoms nor oxygen saturations. Her medications were reviewed and venlafaxine was discontinued because of previous case reports linking it to ILD.

After discontinuing venlafaxine, there was a significant improvement in her dyspnea, fatigue, mobility, and oxygen saturation. The crackles from her lungs had largely cleared except for her bases. By February 19, 2015, she was back to baseline function.

\section{Case series}

The index case led us to review all patients in our practice with symptomatic lung disease who were also using SSRI/ 
SNRIs. Table 1 shows the characteristics and radiological reports for all the people who met the case definition. Five cases had severe symptomatic lung disease (cases 1 [index case], 3, 7, 8, and 9) and were taken off their SSRI/SNRI. Four of the five cases showed significant improvement in cough, mucous production, dyspnea, and wheezing with cessation of what were previously thought to be exacerbations of bronchiectasis and chronic bronchitis. Four of the five cases relapsed with depressive symptoms and had to be put on the non-SSRI/SNRI ADs bupropion and mirtazapine. The estimated median latency between first known exposure to SSRI/SNRIs and presences of abnormalities on CXR and CT was 36 months.

\section{Case-control study}

Table 2 compares characteristics between cases and controls. The mean ages of cases and controls were 89.0 and 88.7 years, respectively ( $p=0.862$ ). For cases and controls, respectively, there were no significant differences between the proportions who were females (75\% vs $72.9 \%$ ) and ever-smoked ( $75 \%$ vs $50.2 \%$ ) mean eGFR ( 53.3 vs $59.1 \mathrm{~mL} / \mathrm{min} / 1.73 \mathrm{~m}^{2}$ ), median CFS (6 vs 6), and presence of neurological problems $(41.7 \%$ vs $50.9 \%)$. There were 10 of $12(83.3 \%)$ cases who used an $\mathrm{SSRI} / \mathrm{SNRI}$ at any time while in the practice, compared to 99 of $273(36.3 \%$ ) controls ( $p=0.002)$. The Mantel-Haenszel odds ratio was $8.79,95 \%$ CI $2.40-32.2(p=0.001)$. For $\mathrm{SSRI} / \mathrm{SNRI}$ users, the median cumulative dose was significantly higher for cases (110.0 p-m) compared to controls (29.5 p-m, $p=0.003)$.

Table 2 Comparison of cases and controls

\begin{tabular}{|c|c|c|c|}
\hline & Cases & Controls & $p$-value \\
\hline Number & 12 & 273 & \\
\hline Age, years - mean (SD) & $89.0(5.0)$ & $88.7(6.4)$ & 0.862 \\
\hline Female - n (\%) & $9(75.0)$ & $199(72.9)$ & 0.871 \\
\hline Ever smoked - n (\%) & $9(75.0)$ & $122(50.2)$ & 0.138 \\
\hline eGFR, $\mathrm{mL} / \mathrm{min} / \mathrm{I} .73 \mathrm{~m}^{2}-$ mean (SD) & $53.3(18.4)$ & $59.1(18.7)$ & 0.315 \\
\hline Clinical Frailty Scale - median & 6 & 6 & 0.950 \\
\hline Neurological problems* & $5(4 \mid .7)$ & $139(50.9)$ & 0.569 \\
\hline Chest X-ray - n (\%) & II (9I.7) & 161 (59.0) & 0.031 \\
\hline Chest X-ray-median & 2.5 & I & 0.003 \\
\hline CT chest $-\mathrm{n}(\%)$ & $8(66.7)$ & $23(8.4)$ & 0.000 \\
\hline CT chest - median & I & 0 & 0.000 \\
\hline SSRI/SNRI ever used - n (\%) & $10(83.3)$ & $99(36.3)$ & 0.002 \\
\hline $\begin{array}{l}\text { SSRI/SNRI person-month exposure } \\
\text { for users only - median }\end{array}$ & 110.0 & 29.5 & 0.003 \\
\hline
\end{tabular}

Note: *Neurological problems included the presence of either dementia, neurodegenerative disease, stroke, or brain injury without dementia.

Abbreviations: SD, standard deviation; n, number; eGFR, estimated glomerular filtration rate; CT, computed tomography; SSRI, selective serotonin reuptake inhibitor; SNRI, serotonin norepinephrine reuptake inhibitor.
Table 3 Frequency of exposure by type of antidepressant for all patients in the study

\begin{tabular}{lll}
\hline & Number & $\%$ \\
\hline Citalopram & 35 & 12.2 \\
Escitalopram & 18 & 6.3 \\
Sertraline & 7 & 2.5 \\
Paroxetine & 5 & 1.8 \\
Fluoxetine & 1 & 0.4 \\
Venlafaxine & 35 & 12.2 \\
Duloxetine & 17 & 5.9 \\
Mirtazapine & 39 & 13.6 \\
Bupropion & 22 & 7.7 \\
Amitriptyline & 3 & 1.0 \\
Nortriptyline & 2 & 0.7 \\
Total & 184 & \\
\hline
\end{tabular}

Table 3 shows the frequency of exposure by the type of AD prescribed. There were $23.2 \%$ of people exposed to SSRIs, $18.1 \%$ to SNRIs, $13.6 \%$ to mirtazapine, $7.7 \%$ to bupropion, and $2.0 \%$ to tricyclic ADs.

The possibility of confounding was tested by examining exposure to SSRI/SNRIs in people with neurological problems. There were 144 people who had neurological problems of whom 65 (45.1\%) were exposed to SSRI/SNRIs compared to 44 of $141(31.2 \%)$ of the people without these conditions $(p=0.022)$. The Mantel-Haenszel odds ratio was $1.8,95 \% \mathrm{CI}$ $1.1-2.9, p=0.016$. For SSRI/SNRI users, the median cumulative dose was $39 \mathrm{p}-\mathrm{m}$ for people with neurological problems compared to $25 \mathrm{p}-\mathrm{m}$ for people without these conditions ( $p=0.453)$. Only cumulative dose of SSRI/SNRIs was significantly associated with being a case $(p=0.001)$ in a multiple logistic regression model that also included neurological problems, smoking, eGFR, and age.

Ascertainment bias was assessed by comparing CT and CXR testing between cases and controls, as well as between SSRI/SNRI exposed and non-exposed. Table 2 shows that cases had significantly more CT and CXR tests compared to controls. Bivariate analysis showed the number of CXRs and CTs were significantly correlated with being a case, practice LOS, cumulative dose of SSRI/SNRI and being exposed to an SSRI/SNRI. Multiple linear regression showed that only being a case was associated with the number of CTs $(p<0.000)$, and both being a case $(p=0.002)$ and LOS $(p<0.000)$ were associated with the number of CXRs. Cumulative dose and SSRI exposure were no longer significantly associated with testing in these models.

\section{Discussion}

This study demonstrates a significant association between using an SSRI/SNRI and development of ILD/B. The 
strength of association (odds ratio 8.79) and difference in median exposure between cases and controls is suggestive that this may be a true association. It appears that the association is not restricted to one drug but may be due to a class effect.

It is estimated that $11 \%$ of the American population $>11$ years old are taking ADs. ${ }^{2}$ Despite this level of exposure in the population, there have only been rare published case reports of drug-induced ILD/B in the nongeriatric population. It is likely that younger populations have greater lung reserve and may need to be on SSRIs/ SNRIs for a significantly longer period of time to develop symptomatic disease. Our patient population is a frail elderly group with multiple comorbidities and a high level of SSRI/ SNRI exposure, which may leave them more vulnerable to development of ILD/B. In an elderly population, it would be easy to miss the association between drug exposure and pulmonary disease due to the high prevalence of non-specific symptoms such as fatigue, cough, dyspnea, and reduced diagnostic intensity. Other factors that may lead to missing this association include: increased prevalence of cognitive impairment affecting reporting of symptoms; fragmentation of care between family doctors and specialists; higher frequency of pulmonary comorbidities with lower lung reserves; and long latency from the time of exposure until the onset of symptomatic disease. Factors that may increase the risk of drug-induced ILD/B in this population include reduced drug clearance from lower GFRs as well as the higher prevalence of polypharmacy with increased risk of drug interaction and accumulation.

Most published case reports of SSRI/SNRI-induced lung damage describe people with severe respiratory problems, most of whom improved clinically and radiologically after withdrawing these drugs. Our cases had a more indolent and chronic presentation and only showed partial improvement in clinical symptoms after withdrawing these drugs. The lack of complete resolution may be due to prolonged exposure with permanent fibrosis in the lungs.

Drugs may cause lung injury by a multitude of nonspecific direct cytotoxic mechanisms and oxidative damage to alveoli, bronchioles, and capillaries as well as via immune mediation. ${ }^{26,27}$ Fluoxetine has been shown to cause ILD in an animal model. ${ }^{28}$ Genetic factors including polymorphisms in MUC5B promoter ${ }^{23}$ may lead to increased susceptibility to lung damage. Similarly, polymorphisms in cytochrome P450 may also lead to variable drug accumulation. ${ }^{29}$

Our findings suggest that at the very least, prescribers should reassess rationale for treating people with mild depression and anxiety. Considerations should be given to using alternative effective treatments such as cognitive behavior therapy. Also, consideration should be given to using the lowest possible dose of $\mathrm{AD}$ and to limit the duration of treatment. Nevertheless, we recommend caution and close monitoring following tapering and cessation of ADs as most of our patients relapsed and needed alternative medications to treat relapse of their depression and anxiety.

\section{Strengths and limitations of this study}

Because of the retrospective design, we were unable to demonstrate a temporal association between exposure to drugs and development of ILD/B. Similarly, one must be cautious interpreting the median latency (36 months) from the time of exposure to SSRI/SNRIs to the development of abnormalities on CXR or CT because testing was not done at regular intervals. However, four of our five most severely affected cases clinically improved with withdrawal of these drugs. It is possible that this may have been spontaneous improvement. However, a number of the case reports demonstrated development of disease after exposure, radiological and clinical improvement with withdrawal of the drug, ${ }^{10-14,16}$ and worsening with rechallenge. ${ }^{15}$

Only $60 \%$ of patients in the study had CXR reports in their charts and $10 \%$ had CT imaging, which could lead to ascertainment bias. Analyses demonstrated a low probability of an ascertainment bias for radiological imaging.

It is not possible to measure the incident risk of developing ILD/B because of the retrospective nature of this study. Nevertheless, 10 of 109 (9.2\%) patients who had been exposed to SSRIs/SNRIs during this study period met the case definition for ILD/B. Even if we restricted the case definition to half of the group with the most severe clinical and $\mathrm{CT}$ findings, this prevalence would not be considered rare. It is possible that the true risk may be higher as people who had longer exposure or more severe reactions may have died or moved to nursing homes, creating a selection bias of survivors.

Our estimation of 1 year of exposure for people who came into the practice on an SSRI/SNRI may have underestimated exposure, as many elderly people are on these drugs for years., ${ }^{2,3}$ It is possible that there was some confounding factors and that insidious chronic lung disease led to a higher risk of depressive symptoms and need for $\mathrm{AD}$ medications. However, this would not explain symptomatic improvement after withdrawing SSRIs/SNRIs, in our patients, and many of the published reports. 
People with neurological problems and dementia have a higher risk of chronic dysphagia/aspiration pneumonitis as well as depression. We tried to control for this potential confounder. Multivariate analysis showed that only cumulative dose of SSRI/SNRIs but not neurological problems was associated with the risk of ILD/B. The small number of cases makes it difficult to control for all possible confounders as well as increases the risk of a type II statistical error.

The strengths of this study include use of all patients, use of patient-level clinical data, validated case definition by independent, blinded radiologists, and actual SSRI/SNRI exposure. The index case had a Naranjo algorithm ${ }^{30}$ score of seven, indicating that venlafaxine probably caused this adverse drug reaction. We were also able to control for some of the known confounding causes of ILD/B.

\section{Conclusion}

Both the incidence of ILD and the usage of SSRIs/SNRIs in the general population are increasing. This study shows a significant association between SSRI/SNRI usage and development of ILD/B in an elderly population. It does not prove cause and effect. Because of the public health implications, future studies are needed to validate these findings.

\section{Acknowledgments}

The authors would like to thank Dr Fiona Manning for suggestions about research questions and reviewing earlier drafts of the manuscript; Priya Rosenberg for assisting with the audit; Professor Jonathon Berkowitz for advice about statistical analysis; and Cliff Cornish, chief librarian of Island Health, for assisting with the literature review. The authors would also like to thank the anonymous patients whose care planning discussions supported the conception of this research question. Without their involvement, this paper would not have been possible.

The lead author affirms that the manuscript is an honest, accurate, and transparent account of the study being reported; that no important aspects of the study have been omitted; and that any discrepancies from the study as planned have been explained.

\section{Author contributions}

All authors contributed toward data analysis, drafting and critically revising the paper and agree to be accountable for all aspects of the work.

\section{Data sharing}

The anonymized dataset is available from the corresponding author upon reasonable request.

\section{Disclosure}

The authors report no conflicts of interest in this work.

\section{References}

1. Kantor ED, Rehm CD, Haas JS, Chan AT, Giovannucci EL. Trends in prescription drug use among adults in the United States from 1999-2012. JAMA. 2015;314(17):1818-1831.

2. Pratt LA, Brody DJ, Gu Q. Antidepressant use in persons aged 12 and over: United States, 2005-2008. NCHS Data Brief. 2011;(76):1-8.

3. Coupland C, Dhiman P, Morriss R, Arthur A, Barton G, Hippisley-Cox J. Antidepressant use and risk of adverse outcomes in older people: population based cohort study. BMJ. 2011;343:d4551.

4. Karkare SU, Bhattacharjee S, Kamble P, Aparasu R. Prevalence and predictors of antidepressant prescribing in nursing home residents in the United States. Am J Geriatr Pharmacother. 2011;9(2):109-119.

5. Carson HJ, Zweigart M, Lueck NE. Death from asthma associated with sertraline overdose. Am J Forensic Med Pathol. 2000;21(3):273-275.

6. Turner RC, Nelson JE, Roberts BT, Gillam DM. Venlafaxine-associated interstitial pneumonitis. Pharmacotherapy. 2005;25(4):626-629.

7. Barnés MT, Bascuñana J, García B, Alvarez-Sala JL. Acute eosinophilic pneumonia associated with antidepressant agents. Pharm World Sci. 1999;21(5):241-242.

8. Espeleta VJ, Moore WH, Kane PB, Baram D. Eosinophilic pneumonia due to duloxetine. Chest. 2007;131(3):901-903.

9. Fleisch MC, Blauer F, Gubler JG, Kuhn M, Scherer TA. Eosinophilic pneumonia and respiratory failure associated with venlafaxine treatment. Eur Respir J. 2000;15(1):205-208.

10. Thornton C, Maher TM, Hansell D, Nicholson AG, Wells AU. Pulmonary fibrosis associated with psychotropic drug therapy: a case report. J Med Case Rep. 2009;3:126.

11. Tsigkaropoulou E, Hatzilia D, Rizos E, et al. Venlafaxine-induced acute eosinophilic pneumonia. Gen Hosp Psychiatry. 2011;33(4) 411.e7-e9.

12. Vázquez MJ, Carretero Quevedo B. Pneumonitis related to venlafaxine. Psychosomatics. 2008;49(1):84-85.

13. Drent M, Singh S, Gorgels AP, et al. Drug-induced pneumonitis and heart failure simultaneously associated with venlafaxine. Am J Respir Crit Care Med. 2003;167(7):958-961.

14. de Kerviler E, Trédaniel J, Revlon G, et al. Fluoxetine-induced pulmonary granulomatosis. Eur Respir J. 1996;9(3):615-617.

15. Torok NI, Donaldson BL, Taji J, Abugiazya A, Assaly R. Diffuse alveolar damage and recurrent respiratory failure secondary to sertraline. Am J Ther. 2012;19(4):e132-e135.

16. Oh S, Cha SI, Kim H, et al. A case of venlafaxine-induced interstitial lung disease. Tuberc Respir Dis (Seoul). 2014;77(2):81-84.

17. Ferreira PG, Costa S, Dias N, Ferreira AJ, Franco F. Simultaneous interstitial pneumonitis and cardiomyopathy induced by venlafaxine. J Bras Pneumol. 2014;40(3):313-318.

18. Coultas DB, Zumwalt RE, Black WC, Sobonya RE. The epidemiology of interstitial lung diseases. Am J Respir Crit Care Med. 1994; 150(4):967-972.

19. Raghu G, Weycker D, Edelsberg J, Bradford WZ, Oster G. Incidence and prevalence of idiopathic pulmonary fibrosis. Am J Respir Crit Care Med. 2006;174(7):810-816.

20. Olson AL, Swigris JJ, Lezotte DC, Norris JM, Wilson CG, Brown KK. Mortality from pulmonary fibrosis increased in the United States from 1992 to 2003. Am J Respir Crit Care Med. 2007;176(3):277-284.

21. Gribbin J, Hubbard RB, Le Jeune I, Smith CJ, West J, Tata LJ. Incidence and mortality of idiopathic pulmonary fibrosis and sarcoidosis in the UK. Thorax. 2006;61(11):980-985.

22. Kornum JB, Christensen S, Grijota M, et al. The incidence of interstitial lung disease 1995-2005: a Danish nationwide population-based study. BMC Pulm Med. 2008;8:24.

23. Araki T, Putman RK, Hatabu H, et al. Development and progression of interstitial lung abnormalities in the Framingham Heart Study. Am J Respir Crit Care Med. 2016;194(12):1514-1522. 
24. Rosenberg T. Acute hospital use, nursing home placement, and mortality in a frail community-dwelling cohort managed with Primary Integrated Interdisciplinary Elder Care at Home. J Am Geriatr Soc. 2012;60(7): 1340-1346.

25. Rockwood K, Song X, MacKnight C, et al. A global clinical measure of fitness and frailty in elderly people. CMAJ. 2005;173(5):489-495.

26. Allen JN. Drug-induced eosinophilic lung disease. Clin Chest Med. 2004;25(1):77-88.

27. Matsuno O. Drug-induced interstitial lung disease: mechanisms and best diagnostic approaches. Respir Res. 2012;13:39.
28. Capelozzi MA, Leick-Maldonado EA, Parra ER, Martins MA, Tibério IF, Capelozzi VL. Morphological and functional determinants of fluoxetine (Prozac)-induced pulmonary disease in an experimental model. Respir Physiol Neurobiol. 2007;156(2):171-178.

29. Chang M, Tybring G, Dahl ML, Lindh JD. Impact of cytochrome P450 2C19 polymorphisms on citalopram/escitalopram exposure: a systematic review and meta-analysis. Clin Pharmacokinet. 2014;53(9):801-811.

30. Naranjo CA, Busto U, Sellers EM, et al. A method for estimating the probability of adverse drug reactions. Clin Pharmacol Ther. 1981;30(2): 239-245.
Clinical Interventions in Aging

\section{Publish your work in this journal}

Clinical Interventions in Aging is an international, peer-reviewed journal focusing on evidence-based reports on the value or lack thereof of treatments intended to prevent or delay the onset of maladaptive correlates of aging in human beings. This journal is indexed on PubMed Central, MedLine,

\section{Dovepress}

CAS, Scopus and the Elsevier Bibliographic databases. The manuscript management system is completely online and includes a very quick and fair peer-review system, which is all easy to use. Visit http://www.dovepress. com/testimonials.php to read real quotes from published authors. 